\title{
Quantification of Benazepril Hydrochloride and Hydrochlorothiazide in Tablet Dosage Form by Simultaneous Equation Spectrophotometric Method
}

\author{
Varsha Parmar, Usmangani Chhalotiya, Dimal Shah, Kashyap Bhatt, and Sunil Baldania \\ Department of Pharmaceutical Chemistry and Analysis, Indukaka Ipcowala College of Pharmacy, Beyond GIDC Phase IV, \\ P.O. Bar 53, Vithal Udyog nagar, New Vallabh Vidyanagar, Anand, Gujarat 388 121, India
}

Correspondence should be addressed to Varsha Parmar; varsha.parmar1416@gmail.com

Received 26 March 2013; Revised 5 August 2013; Accepted 9 August 2013

Academic Editor: Guang-Fu Yang

Copyright (C) 2013 Varsha Parmar et al. This is an open access article distributed under the Creative Commons Attribution License, which permits unrestricted use, distribution, and reproduction in any medium, provided the original work is properly cited.

\begin{abstract}
Simple, accurate, precise, reproducible, requiring no prior separation, and economical procedures for simultaneous estimation of benazepril hydrochloride (BEN) and Hydrochlorothiazide (HCT) in tablet dosage form have been developed. Simultaneous equation method employs for estimation of both drugs in methanol at $240 \mathrm{~nm}$ and $270 \mathrm{~nm}$ as two analytical wavelengths. BEN and HCT at their respective $\lambda_{\max }(240 \mathrm{~nm}$ and $270 \mathrm{~nm})$ show linearity in a concentration range of $2-12 \mu \mathrm{g} / \mathrm{mL}$ and $4-14 \mu \mathrm{g} / \mathrm{mL}$. Recovery studies for BEN are 100.0-100.6\% and $99.8-100.0 \%$ for HCT in the case of simultaneous equation method confirming the accuracy of the proposed method. The proposed method is recommended for routine analysis since it is rapid, simple, accurate and also sensitive and specific.
\end{abstract}

\section{Introduction}

Benazepril hydrochloride (BEN) is chemically 3-[[1(ethoxycarbonyl)-3-phenyl-(1S)-propyl]amino]-2,3,4,5-tetrahydro-2-oxo-1H-1-(3S)-benzazepine-1-acetic acid monohydrochloride (Figure 1(a)). The empirical formula of BEN is $\mathrm{C}_{24} \mathrm{H}_{28} \mathrm{~N}_{2} \mathrm{O}_{5} \cdot \mathrm{HCl}$ with a molecular weight of $460.96 \mathrm{~g} / \mathrm{mole}$ [1]. It is an angiotensin converting enzyme. It is used as antihypertensive agent.

Hydrochlorothiazide (HCT) is chemically 6-chloro-3,4dihydro-2H-1,2,4-benzothiadiazine-7-sulfonamide 1,1-dioxide (Figure 1(b)). The empirical formula is $\mathrm{C}_{7} \mathrm{H}_{8} \mathrm{ClN}_{3} \mathrm{O}_{4} \mathrm{~S}_{2}$ with a molecular weight $297.73 \mathrm{~g} / \mathrm{mole}$ [2]. It is a diuretic agent.

BEN and HCT are official in the british Pharmacopeia and the Indian Pharmacopeia. Many methods have been reported in the literature for both determination of BEN, individually and with other drugs in combination [317]. However, there is no UV spectrophotometric method reported for the simultaneous estimation of BEN and HCT in pharmaceutical preparations in the literature survey. The objective of the present work is to develop and validate new analytical methods for simultaneous determination of BEN and HCT in tablet dosage form.

\section{Experimental}

2.1. Materials and Methods. A double-beam Shimadzu UVvisible spectrophotometer 1700 (Pharma spec), with wavelength accuracy of $\pm 0.5 \mathrm{~nm}$ and a pair of $1 \mathrm{~cm}$ matched quartz cells, was used to measure absorbance of the resulting solution. All weighing was done on an electronic balance (Shimadzu BL-220H). All statistical calculations were carried out using Microsoft Excel 2007 analytical tool.

Analytically pure BEN and HCT were procured as gift sample from Dishman Pharmaceuticals Ltd. and Cadila Pharmaceutical Pvt. Ltd. (Ahmedabad, India). Methanol (E. Merck, Mumbai, India) analytical grade was used as a diluent. Tablet formulation (Lotensin HCT, Novartis Pharmaceutical Pvt. Ltd.) containing labelled amount of $10 \mathrm{mg}$ of benazepril hydrochloride and $12.5 \mathrm{mg}$ of hydrochlorothiazide was purchased from local market. 
<smiles>CCC(=O)[C@H](CCc1ccc(Cl)cc1)NC(=O)[C@H](C)N(CC(=O)O)c1ccccc1CC</smiles>

(a)

(b)

FIGURE 1: (a) Structure of hydrochlorothiazide. (b) Structure of benazepril hydrochloride.

2.2. Preparation of Solutions. Accurately weighed $100 \mathrm{mg}$ of BEN and HCT standards was transferred to separate $100 \mathrm{~mL}$ volumetric flasks and dissolved in $50 \mathrm{~mL}$ Methanol. The flasks were shaken, and the volume was made up to the mark with methanol to give solutions containing $1000 \mu \mathrm{g} / \mathrm{mL} \mathrm{BEN} \mathrm{and}$ $1000 \mu \mathrm{g} / \mathrm{mL}$ HCT, respectively.

2.3. Methodology. Selection of analytical wavelengths was done by taking pure samples of BEN and HCT, which were separately dissolved in methanol, to give two solutions of $10 \mu \mathrm{g} / \mathrm{mL}$, respectively. They were scanned in the wavelength range of 200-400 $\mathrm{nm}$. From the overlain spectra (Figure 2), wavelengths of 240 and $270 \mathrm{~nm}$ were selected for the formation of simultaneous equations. For constructing a calibration curve, two series of different concentrations in range of 2$12 \mu \mathrm{g} / \mathrm{mL}$ for BEN and $4-14 \mu \mathrm{g} / \mathrm{mL}$ for HCT were prepared from stock solutions. The calibration curves were plotted at 240 and $270 \mathrm{~nm}$. The absorptivities $(\mathrm{A} 1 \%, 1 \mathrm{~cm})$ of both drugs at both wavelengths were determined. These calculated values were the mean of five independent determinations. Concentrations in the sample were obtained by using the following equations:

$$
\begin{aligned}
& C_{x}=\frac{A_{1} a y_{2}-A_{2} a y_{1}}{a x_{1} a y_{2}-a x_{2} a y_{1}} \\
& C_{y}=\frac{A_{1} a x_{2}-A_{2} a x_{1}}{a y_{1} a x_{2}-a y_{2} a x_{1}},
\end{aligned}
$$

where $A_{1}$ and $A_{2}$ are absorbance of mixtures at $240 \mathrm{~nm}$ and $270 \mathrm{~nm}$, respectively; $a x_{1}$ and $a x_{2}$ are absorptivities of BEN at $\lambda_{1}$ and $\lambda_{2}$, respectively, $a y_{1}$ and $a y_{2}$ are absorptivities of HCT at $\lambda_{1}$ and $\lambda_{2}$ respectively. $C_{x}$ and $C_{y}$ are concentrations of BEN and HCT, respectively.

2.4. Method Validation. The proposed method was validated according to the International Conference on Harmonization (ICH) guidelines [18].

2.5. Linearity and Range. Developed analytical method shows linearity response over the range of $2-12 \mu \mathrm{g} / \mathrm{mL}$ for BEN and $4-14 \mu \mathrm{g} / \mathrm{mL}$ for HCT at $240 \mathrm{~nm}$ and $270 \mathrm{~nm}$ respectively.

2.6. Precision. The intraday and interday precision study of the proposed simultaneous equation spectrophotometric

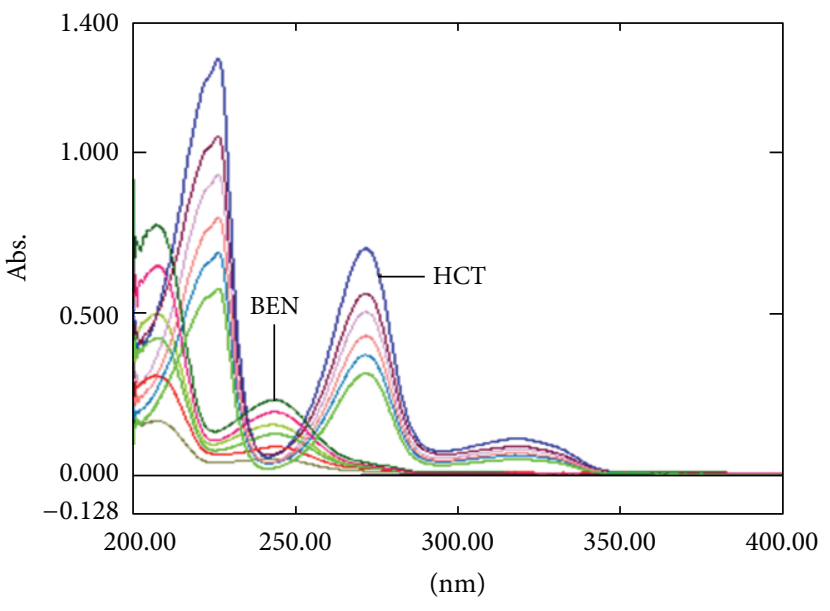

FIGURE 2: Overlain spectrum of BEN and HCT in Methanol.

TABLE 1: Summary of validation parameters.

\begin{tabular}{lcc}
\hline Parameters & BEN & HCT \\
\hline Limit of detection & 0.103 & 0.025 \\
Limit of quantitation & 0.312 & 0.075 \\
Accuracy (\%) & $100.0-100.6$ & $99.8-100.2$ \\
Precision & & \\
$\quad$ Intraday $(n=3)$ & $0.47-0.74 \%$ & $0.13-0.24 \%$ \\
$\quad$ Interday $(n=3)$ & $0.30-0.81 \%$ & $0.18-0.40 \%$ \\
Repeatability (RSD, $n=6)$ & $1.32 \%$ & $1.96 \%$ \\
Specificity & Specific & Specific \\
Robustness & Robust & Robust \\
Solvent suitability & Suitable for 24 hrs. & Suitable for 24 hrs.
\end{tabular}

TABLE 2: Statistical data of BEN and HCT.

\begin{tabular}{lcc}
\hline Parameters & BEN at $240 \mathrm{~nm}$ & HCT at $270 \mathrm{~nm}$ \\
\hline Linear range & $2-12 \mu \mathrm{g} / \mathrm{mL}$ & $4-14 \mu \mathrm{g} / \mathrm{mL}$ \\
Slope & 0.0181 & 0.05 \\
Intercept & 0.0129 & 0.035 \\
Standard deviation of intercept & 0.0031 & 0.0010 \\
Standard deviation of slope & 0.0005 & 0.0019 \\
Regression coefficient $\left(R^{2}\right)$ & 0.9997 & 0.9988 \\
\hline
\end{tabular}

method was carried out by estimating responses three times on the same day and on three different days (first, second, and 
TABLE 3: Determination of precision for BEN.

\begin{tabular}{|c|c|c|c|c|c|}
\hline BEN & Conc. $(\mu \mathrm{g} / \mathrm{mL})$ & Intraday mean $\pm \mathrm{SD}(n=3)$ & $\%$ RSD & Interday mean $\pm \mathrm{SD}(n=3)$ & $\% \mathrm{RSD}$ \\
\hline \multirow{3}{*}{ At $240 \mathrm{~nm}$} & 6 & $0.12267 \pm 0.00058$ & 0.47 & $0.124 \pm 0.001$ & 0.81 \\
\hline & 8 & $0.15533 \pm 0.00115$ & 0.74 & $0.15533 \pm 0.00058$ & 0.37 \\
\hline & 10 & $0.196 \pm 0.001$ & 0.51 & $0.19533 \pm 0.00058$ & 0.30 \\
\hline \multirow{3}{*}{ At $270 \mathrm{~nm}$} & 6 & $0.03067 \pm 0.00058$ & 1.88 & $0.03067 \pm 0.00058$ & 1.88 \\
\hline & 8 & $0.3633 \pm 0.00058$ & 1.59 & $0.03667 \pm 0.00058$ & 1.58 \\
\hline & 10 & $0.04367 \pm 0.00058$ & 1.32 & $0.04767 \pm 0.00058$ & 1.21 \\
\hline
\end{tabular}

TABLE 4: Determination of precision for HCT.

\begin{tabular}{|c|c|c|c|c|c|}
\hline HCT & Conc. $(\mu \mathrm{g} / \mathrm{mL})$ & Intraday mean $\pm \mathrm{SD}(n=3)$ & $\%$ RSD & Interday mean $\pm \mathrm{SD}(n=3)$ & $\%$ RSD \\
\hline \multirow{3}{*}{ At $240 \mathrm{~nm}$} & 8 & $0.03467 \pm 0.00058$ & 0.017 & $0.03433 \pm 0.00058$ & 1.68 \\
\hline & 10 & $0.042 \pm 0.001$ & 0.024 & $0.04267 \pm 0.00058$ & 1.35 \\
\hline & 12 & $0.217 \pm 0.28232$ & 0.18 & $0.05433 \pm 0.00058$ & 1.06 \\
\hline \multirow{3}{*}{ At $270 \mathrm{~nm}$} & 8 & $0.44333 \pm 0.00058$ & 0.13 & $0.44467 \pm 0.00153$ & 0.34 \\
\hline & 10 & $0.526 \pm 0.001$ & 0.19 & $0.52567 \pm 0.00208$ & 0.40 \\
\hline & 12 & $0.63367 \pm 0.00153$ & 0.24 & $0.63333 \pm 0.00115$ & 0.18 \\
\hline
\end{tabular}

third days) for three different concentrations of $\operatorname{BEN}(6,8$, and $10 \mu \mathrm{g} / \mathrm{mL})$ and $\operatorname{HCT}(8,10,12 \mu \mathrm{g} / \mathrm{mL})$, and the results are reported in terms of percentage relative standard deviation (\%RSD).

2.7. Accuracy. The accuracy of the method was determined by calculating recoveries of BEN and HCT by the method of standard additions. Known amount of BEN (50\%, 100\%, and $150 \%)$ and HCT $(50 \%, 100 \%$, and $150 \%)$ was added to a pre quantified sample solutions, and the amounts of BEN and HCT were estimated by measuring the response at the appropriate wavelengths. The recovery was verified by estimation of drugs in triplicate preparations at each specified concentration level.

2.8. $L O D$ and LOQ. Calibration curve was repeated 5 times, and the standard deviation (SD) of the intercepts was calculated. Then LOD and LOQ were measured as follows:

$$
\begin{aligned}
& \mathrm{LOD}=3.3 \times \frac{\sigma}{S}, \\
& \mathrm{LOQ}=10 \times \frac{\sigma}{S},
\end{aligned}
$$

where $\sigma$ is the standard deviation of the $y$-intercept $S$ is the slope of the calibration curve.

2.9. Solution Stability. Solution stability of the method was studied by observing the stability of both drug solutions at $25 \pm 2^{\circ} \mathrm{C}$ for $24 \mathrm{~h}$.

2.10. Analysis of Marketed Formulation. The pharmaceutical dosage form used in this study was Lotensin HCT tablets with a content of $10 \mathrm{mg}$ BEN and $12.5 \mathrm{mg}$ HCT (as per USP) per tablet. Twenty tablets of brand Lotencin HCT tablets were weighed and finely powdered. Accurately weighed tablet powder equivalent to $10 \mathrm{mg}$ was taken in $100 \mathrm{~mL}$ volumetric flask. Few $\mathrm{mL}$ of methanol was added and sonicated for $5 \mathrm{~min}$. The volume was made up to the mark with methanol. Aliquot portion of this solution was further diluted to achieve final concentration of $10 \mu \mathrm{g} / \mathrm{mL}$ for BEN and HCT. The absorbances were noted at respective wavelengths. The concentration of each drug in tablet formulation was determined using the above methods.

\section{Result and Discussion}

A simultaneous equation spectrophotometric method was successfully developed for the determination of BEN and HCT from their combined dosage form.

The proposed simultaneous equation method shows good linearity in the concentration range of $2-12 \mu \mathrm{g} / \mathrm{mL}$ for BEN and $4-14 \mu \mathrm{g} / \mathrm{mL}$ for HCT with correlation coefficient 0.9997 of BEN and 0.9988 for HCT, respectively (Table 2).

The \%RSD values for BEN and HCT were found to be $1.32 \%$ and $1.96 \%$, respectively. The low values of relative standard deviation (less than $2 \%$ ) indicate that the proposed method is repeatable. The \%RSD values for intraday study were found to be $0.47-0.74 \%$ and $0.13-0.24 \%$ for BEN and $\mathrm{HCT}$, respectively. The \%RSD values for interday study were found to be $0.30-0.81 \%$ and $0.18-0.40 \%$ for BEN and HCT, respectively. The low RSD value indicates that the proposed method is precise (Tables 3 and 4). The detection limit of BEN and HCT were 0.103 and $0.025 \mu \mathrm{g} / \mathrm{mL}$, while quantitation limits of BEN and HCT were 0.312 and $0.075 \mu \mathrm{g} / \mathrm{mL}$, respectively. The above data shows that a nanogram quantity of both the drugs can be accurately and precisely determined. The validation parameters are summarized in Table 1 .

The accuracy of the method was determined by calculating recoveries of BEN and HCT by the method of standard additions. The percent recovery was found to be $100.0 \%-$ $100.6 \%$ for BEN and $99.8 \%-100.2 \%$ for HCT (Table 5 ). The results of recovery studies indicate that the proposed method is accurate. 
TABle 5: Determination of accuracy.

\begin{tabular}{|c|c|c|c|c|c|c|}
\hline \multirow{2}{*}{$\%$ level } & \multicolumn{2}{|c|}{ Amount of drug added $(\mu \mathrm{g} / \mathrm{mL})$} & \multicolumn{2}{|c|}{ Recovered amount of drug $(\mu \mathrm{g} / \mathrm{mL})$} & \multicolumn{2}{|c|}{$\%$ recovery } \\
\hline & $\mathrm{BEN}(\mu \mathrm{g} / \mathrm{mL})$ & $\operatorname{HCT}(\mu \mathrm{g} / \mathrm{mL})$ & $\mathrm{BEN}(\mu \mathrm{g} / \mathrm{mL})$ & $\operatorname{HCT}(\mu \mathrm{g} / \mathrm{mL})$ & BEN & HCT \\
\hline 50 & 6 & 6 & 6.04 & 6.00 & 100.6 & 100.2 \\
\hline 100 & 8 & 8 & 8.01 & 7.98 & 100.1 & 99.89 \\
\hline 150 & 10 & 10 & 10.00 & 9.98 & 100.0 & 99.9 \\
\hline
\end{tabular}

TABLE 6: Assay results of marketed formulation.

\begin{tabular}{lccccc}
\hline \multirow{2}{*}{ Formulation } & \multicolumn{2}{c}{ Actual concentration $(\mu \mathrm{g} / \mathrm{mL})$} & \multicolumn{2}{c}{ Amount obtained $(\mu \mathrm{g} / \mathrm{mL})$} & \% BEN \\
& BEN & HCT & BEN & HCT & \% HCT \\
\hline Tablet & 4.0 & 5.0 & 3.90 & 4.97 & $98.25 \%$ \\
\hline
\end{tabular}

The proposed validated method was successfully applied to determine BEN and HCT in tablet dosage form. The results obtained for BEN and HCT were comparable with the corresponding labelled amounts (Table 6). No interference of the excipients with the absorbance of interest appeared; hence the proposed method is applicable for the routine simultaneous estimation of BEN and HCT in pharmaceutical dosage forms.

\section{Conclusions}

Sensitive, precise, and accurate simultaneous UV spectroscopic method was developed and validated. The proposed method is accurate, precise, reproducible, and economic and can be successfully used for routine analysis of simultaneous estimations of BEN and HCT. The method was validated as per the ICH guidelines in terms of specificity, linearity, accuracy, precision, limits of detection (LOD) and limits of quantification (LOQ), and robustness. The proposed method can be used for quality control assay of BEN and HCT in their pharmaceutical dosage form.

\section{Conflict of Interests}

All authors do not have conflict of interests.

\section{Acknowledgments}

The authors are thankful to Dishman Pharmaceuticals Ltd. for providing BEN and Cadila Pharmaceutical Pvt. Ltd. (Ahmedabad, India) for providing HCT as gratis samples. The authors are also heartily thankful to Indukaka Ipcowala College of Pharmacy, New Vallabh Vidyanagar, Anand, for funding the entire project and providing the necessary facilities for research work.

\section{References}

[1] British Pharmacopoeia 2011, vol. 2,The Department of Health, Social Services and Public Safety, pp. 225-226, 2011.

[2] Indian Pharmacopoeia 2007, vol. 2, Government of India, The Indian Pharmacopoeia Commission, Ghaziabad, Ministry of Health \& Family Welfare, pp. 576-578, 2007.
[3] P. Y. Pawar, R. S. Joshi, V. Sandhan, S. Wagh, and K. Jangale, "Simultaneous spectrophotometric estimation of amlodipine besylate and benazepril $\mathrm{HCl}$ in pure and pharmaceutical dosage form," Der Pharmacia Lettre, vol. 3, no. 3, pp. 397-403, 2011.

[4] K. R. Naidu, U. N. Kale, and M. S. Shingare, "Stability indicating RP-HPLC method for simultaneous determination of amlodipine and benazepril hydrochloride from their combination drug product," Journal of Pharmaceutical and Biomedical Analysis, vol. 39, no. 1-2, pp. 147-155, 2005.

[5] M. Sarat, P. M. krishna, and C. Rambabu, "Development and validation of RP-HPLC method for simultaneous estimaton of amlodipine besyate and benazepril $\mathrm{Hcl}$ in tablet," International Journal of Current Pharmaceutical Research, vol. 4, no. 3, pp. 8084, 2012.

[6] K. Safeer, B. Anbarasi, and N. S. Kumar, "Analytical method development and validation of amlodipine and hydrochlorothiazide in combined dosage form by RP-HPLC," International Journal of ChemTech Research, vol. 2, no. 1, pp. 21-25, 2010.

[7] G. Patel, S. Patel, D. Prajapiti, and R. Mehta, "RP-HPLC method for simultaneous estimation of amlodipine besylate and hydrochlorothiazide in combined dosage forms," Stamford Journal of Pharmaceutical Sciences, vol. 3, no. 1, pp. 49-35, 2010.

[8] L. A. Rao and R. V. Bhaskara, "Simultaneous estimation of valsarten and hydrochlorthiazide in tablets by RP-HPLC method," Intnational Journal Pharmaceutical \& Industrial Reserch, vol. 1, no. 3, pp. 170-174, 2011.

[9] M. Kharoaf, N. Malkieh, M. Abualhasan, R. Shubitah, N. Jaradat, and A. N. Zaid, "Tablet formulation and development of a validated stability indicating HPLC method for quantification of valsarten and hydrochlorthiazide combination," International Journal of Pharmacy and Pharmaceutical Sciences, vol. 4, pp. 683-687, 2012.

[10] A. R. Chabukswar, S. C. Jagdale, B. S. Kuchekar et al., "Development and validation of a RP-HPLC method for simultaneous estimation of hydrochlorothiazide and irbesartan," Der Pharma Chemica, vol. 2, no. 4, pp. 148-156, 2010.

[11] R. Rosangluaia, P. Shanmugasundaram, and M. Velraj, "Validated HPTLC method for simultaneous estimation of irbesartan and hydrochlorthiazide in a tablet dosage form," Der Pharma Chemica, vol. 3, no. 5, pp. 310-317, 2011.

[12] S. Brijesh, D. K. Patel, and S. K. Ghosh, "Development of reverse-phase HPLC method for simultaneous analysis of metoprolol succinate and hydrochlorothiazide in a tablet formulation," Tropical Journal of Pharmaceutical Research, vol. 8, no. 6, pp. 539-543, 2009. 
[13] S. T. Kumbhar, G. K. Chougule, V. S. Tegeli, G. B. Gajeli, V. S. Thorat, and U. S. Shivsharan, "A validated HPTLC method for simultaneous quantification of nebivolol and hydrochlorothiazide in bulk and tablet formulation," International Journal of Pharmaceutical Sciences and Drug Research, vol. 3, no. 1, pp. 6266, 2011.

[14] Y. Gupta, A. Shrivastava, D. Duggal, A. Patel, and S. Agrawal, "A new RP-HPLC method for simultaneous estimation of nebivolol hydrochloride and hydrochlorthiazide in dosage forms," Journal Young Pharmacist, vol. 1, no. 3, pp. 264-269, 2009.

[15] S. A. Hapse, V. S. Wagh, P. T. Kadaskar, M. D. Dokhe, and A. S. Shirsath, "Spectrophotometric estimation and validation of hydrochlorothiazide in tablet dosage forms by using different solvents," Der Pharma Chemica, vol. 4, no. 1, pp. 10-114, 2012.

[16] A. El-Gindy, A. Ashour, L. Abdel-Fattah, and M. M. Shabana, "Application of LC and HPTLC-densitometry for the simultaneous determination of benazepril hydrochloride and hydrochlorothiazide," Journal of Pharmaceutical and Biomedical Analysis, vol. 25, no. 2, pp. 171-179, 2001.

[17] I. E. Panderi and M. Parissi-Poulou, "Simultaneous determination of benazepril hydrochloride and hydrochlorothiazide by micro-bore liquid chromatography," Journal of Pharmaceutical and Biomedical Analysis, vol. 21, no. 5, pp. 1017-1024, 1999.

[18] "Validation of analytical procedures: methodology," in $\mathrm{ICH}$ Harmonized Tripartite Guidelines, 2005. 

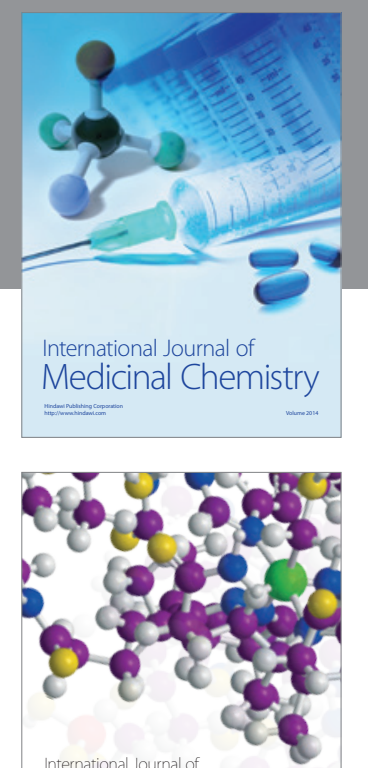

\section{Carbohydrate} Chemistry

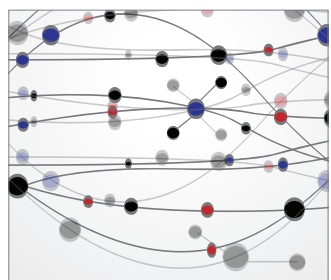

The Scientific World Journal
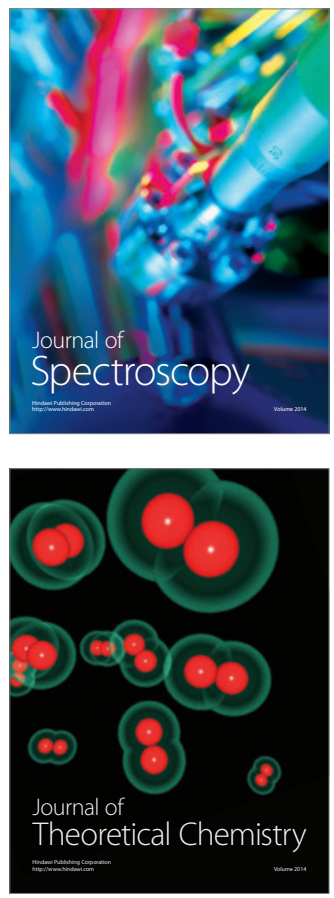
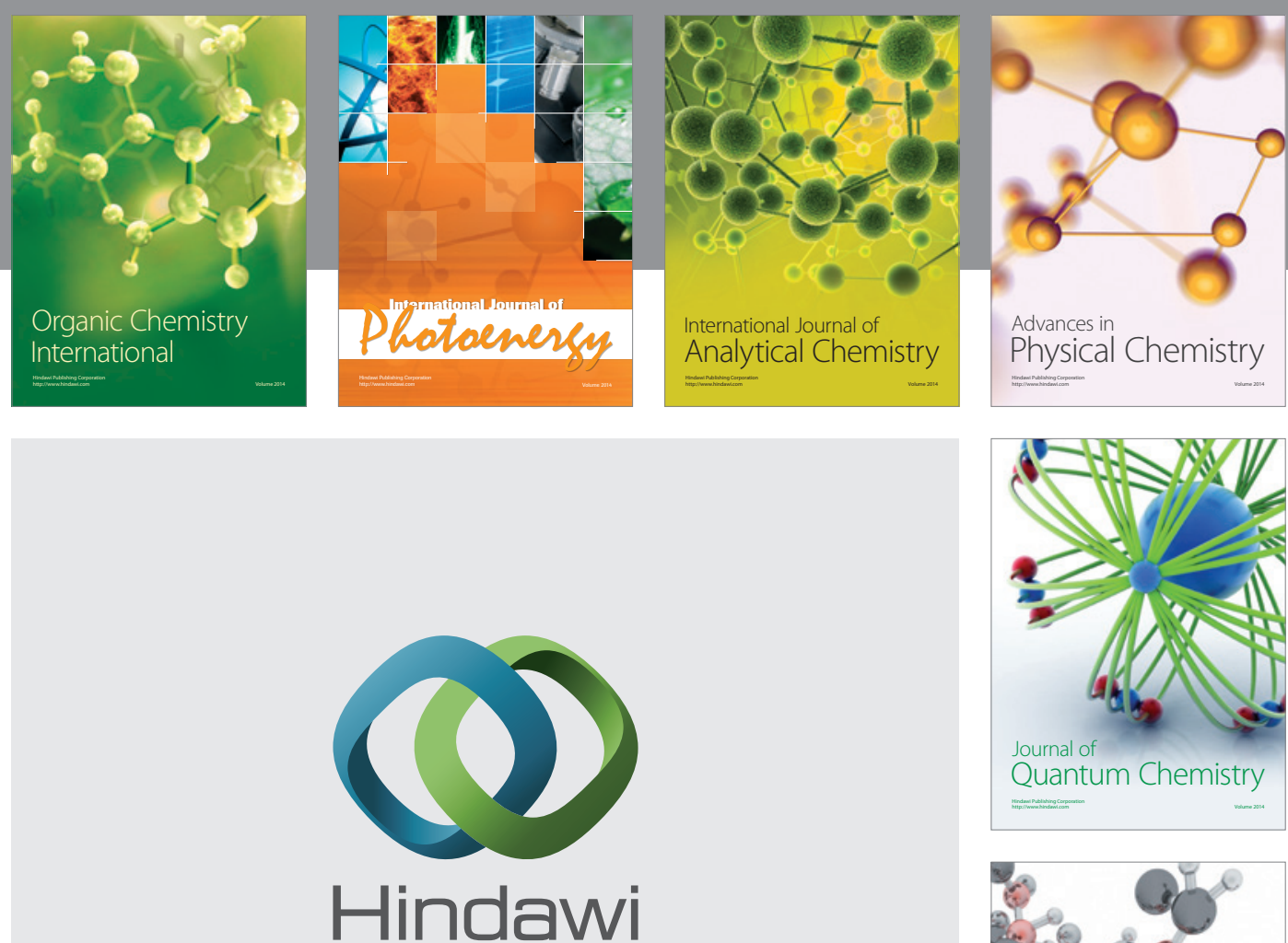

Submit your manuscripts at

http://www.hindawi.com

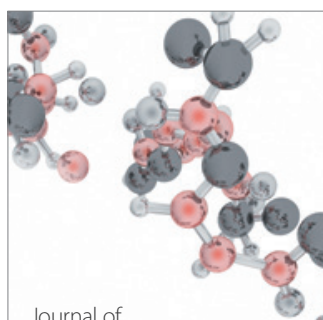

Analytical Methods

in Chemistry

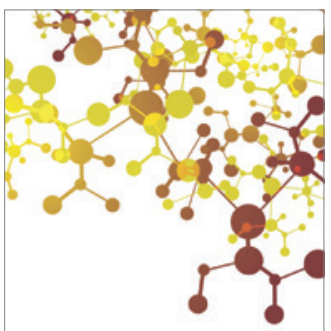

Journal of

Applied Chemistry

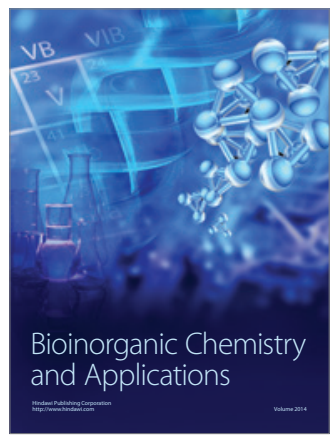

Inorganic Chemistry
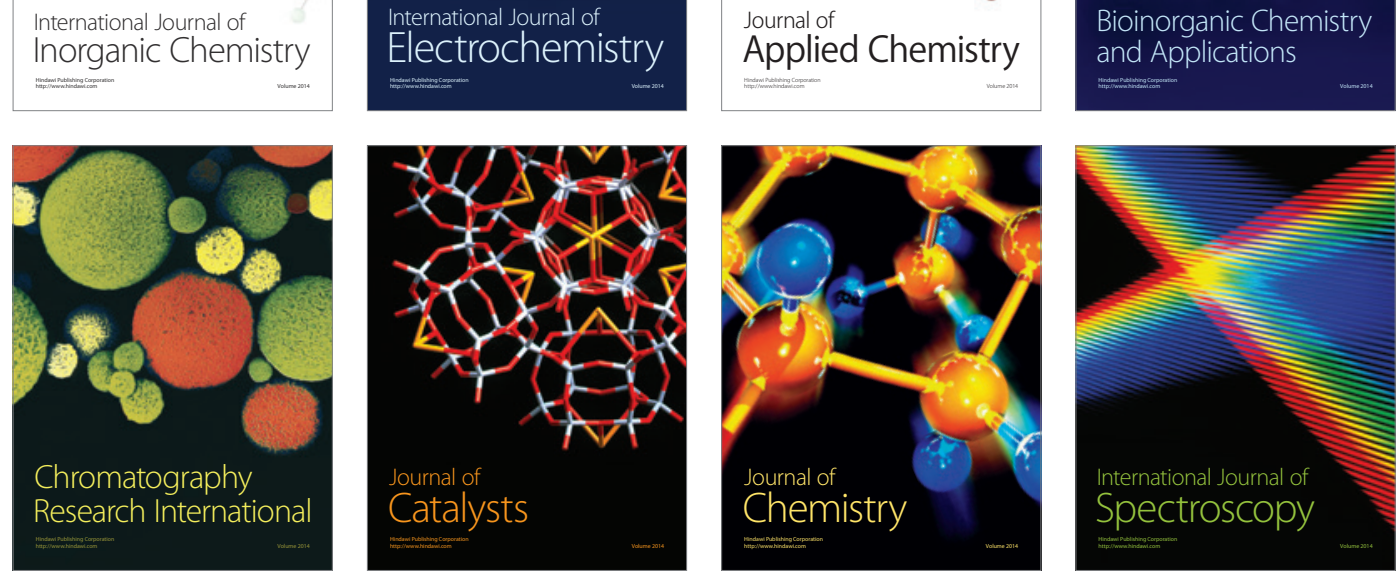